\title{
Readiness in Implementing Student-centred Learning (SCL): An Insight to Developing a Problem-based Learning (PBL) Module
}

\author{
Mohamad Termizi Borhan ${ }^{1,2, *}$, Salmiza Saleh ${ }^{2}$, Agnes Tan Shek Li ${ }^{1}$, Eng Tek Ong ${ }^{1}$ \\ ${ }^{1}$ Faculty of Science and Mathematics, Universiti Pendidikan Sultan Idris, Malaysia \\ ${ }^{2}$ School of Educational Studies, Universiti Sains Malaysia, Malaysia
}

Received October 21, 2019; Revised December 2, 2019; Accepted December 4, 2019

Copyright $\bigcirc 2020$ by authors, all rights reserved. Authors agree that this article remains permanently open access under the terms of the Creative Commons Attribution License 4.0 International License

\begin{abstract}
Focus of current Malaysia Education Blueprint (2013-2025) is on SCL. The blueprint can serve as a good reference material but implementing SCL is largely on the shoulders of the school administrators and senior teachers involved in decision making. This paper aims to unravel the readiness of a Malaysian secondary school to implement and adopt SCL. The findings were subsequently used to provide insight on the development of a problem-based learning (PBL) module for a secondary science curriculum. This paper concerns a case study research which was conducted in a national type secondary school. The sample involved in this study was school administrators and senior science teachers. In-depth, semi-structured interviews were carried out to gain detailed information on the school's readiness to implement SCL. Interviews were transcribed and cross-case comparisons were made to compare and contrast the participants' responses before themes across the interviews data were generated. Three main themes were derived from the analysis, namely (i) knowledge and awareness on SCL, (ii) optimism towards SCL, and (iii) challenges and misinterpretation on SCL. This information provides insights into developing a PBL module specific for Malaysian science curriculum that contains the elements of PBL scenario, facilitations, training, PBL guide and support. Significance: This paper proposes insights for PBL module development that derived from empirical research findings. Therefore, the insights are well grounded and reflective of the current practice of SCL in school which in turn translate into it is effectiveness and feasibility.
\end{abstract}

Keywords Problem-based Learning (PBL), School Readiness, Student-centred Learning, School Administrators

\section{Introduction}

The National Education Blueprint (Pelan Pengajian Pendidikan Malaysia 2013-2025) has emphasised on a balanced education that focuses on transforming education from being teacher-centred to student-centred through various measures. The launching of the blueprint has reaffirmed the implementation of new standards in both primary and secondary schools. The new standards of curriculum known as Kurikulum Standard Sekolah Menengah (KSSM) (secondary school curriculum standards) and Kurikulum Standard Sekolah Rendah (KSSR) (primary school curriculum standards) focus on developing a balanced set of knowledge and skills among learners, such as creative and critical thinking skills, innovativeness, problem-solving skill, and leadership skill. Such efforts indicate a shift of attention towards student-centred learning (SCL). However, the question that arises is how ready the schools are to implement SCL as advocated in the blueprint? The extent to which the schools are ready to embrace and practice SCL has been a dilemma discussed in Malaysia. A national education blueprint may be the main reference for transforming a school pedagogy towards SCL, but implementing the recommendations in the blueprint in a school environment may not be as linear as expected. Such a dilemma would create a unique challenge according to a school's norms and ethos. Therefore, it is important to understand the readiness of the schools to implement SCL. As such, this study intends to document a school's readiness to embrace SCL in an effort to ensure that the aims of SCL in the blueprint are achievable. Specifically, this paper aims to answer the following question:

1. What is the state of the school administrators' readiness to implement SCL?

2. How can the information on school readiness be utilised in developing the PBL modules? 
SCL is a general term that could refer to various teaching and learning approaches. A range of potential definitions of student-centred learning may be identified in the literature. This is because the researchers and practitioners define it form different dimension of teaching and learning process. For the purpose of this study, student centred learning from Cannon and Newbie (2000) provides a good foundation. They define SCL as:

ways of thinking and learning that emphasize student responsibility and activity in learning rather than what the teachers are doing. Essentially SCL has student responsibility and activity at its heart, in contrast to a strong emphasis on teacher control and coverage of academic content in much conventional, didactic teaching.

SCL stands on the premise of (i) the reliance on active rather than passive learning, (ii) emphasis on deep learning and understanding, (iii) increased responsibility and accountability on the part of the student, (iv) increased sense of autonomy in the student, (v) interdependence between teacher and learner, (vi) mutual respect within the learner-teacher relationship, and (vii) a reflexive approach to the teaching and learning process on the part of both the teacher and the student. The shift from the emphasis on teaching to the emphasis on learning has accelerated the notion of SCL, implying thus that students should be actively constructing their own learning and be empowered to arrive at their learning goals. Most educators would agree that developing and implementing SCL has become more of a necessity and norm rather that an innovative approach in teaching and learning. The traditional classroom where student sit quietly while the teacher pour vast amount of knowledge is no longer relevant.

The characteristics and principles of SCL are aligned with various teaching and learning methods that are currently practiced in a teaching and learning process, such as inquiry-based learning, case-based instruction, problem-based learning (PBL), project-based learning, and discovery learning. The Malaysian Education Blueprint explicitly recommends three main teaching and learning approaches as measures in STEM clusters, namely, project-based learning (PjBL), problem-based learning (PBL), and inquiry learning. PBL is an instructional method that challenges students to "learn to learn," and to work cooperatively in groups to find solutions to real-world problems (Duch et al., 2001). Borhan (2012) defines PBL as innovative teaching approach that are able to develop learners with interdisciplinary knowledge and problem solving strategies. Based on both definitions, PBL involve group learning in which students are cooperatively dealing with the innovative problems yet contextual to come out with interdisciplinary solutions.

Nevertheless, this paper focuses only on the insights for PBL module development, which are drawn from the readiness of school administrators in implementing SCL in school.

\section{Methodology}

This is a case study research. The setting of the study is a national type secondary school in Hilir Perak, Malaysia. Case study was deemed as an appropriate research design as the study aimed to explore a phenomenon in a specific geographical boundary. In particular, a qualitative and exploratory study was carried out to understand a school's readiness to implement SCL, particularly from the perspective of the school's administrators. The sample consisted of the schools' principal, head of science department, head of panel of chemistry, and head of panel of physics. The major criteria for choosing the samples were as follows: the subject/course (science-based) they have taught in secondary school and the number of years they have been involved in teaching. According to Cuban (1991), educators with many years of teaching experience will be in a better position to evaluate an instructional practice. In this study, our focus was to inquire the extent to which the school is ready to implement SCL as proposed in the blueprint.

In depth, semi-structured interview was adopted to gather information for the study. The interviews were utilised to gain rich and detailed information from the research sample. An interview protocol was prepared prior to the interview sessions to guide the researchers during the interview process, although the actual sessions may not necessarily comply with the protocol. In other words, the flow of the interviews depended on the feedback given by the samples. An interview method allowed the samples to substantially express their views using their own words. A probing method was also adopted during the interview to obtain relevant answers from the samples besides encouraging a lively discussion. The interviews were held in a quiet and convenient place, and the samples were informed that their names were identified by pseudonyms in the study and other information will be kept confidential. No time limit was given for each interview. Each session was audio-recorded and the conversation was later transcribed for analysis purposes.

Inductive qualitative data analysis was used to analyse the interview data. All the interviews were transcribed and the samples were required to verify that the transcribed interviews were their genuine responses. In the analysis process, the interviews transcripts were first read thoroughly to get a general idea about the interviews. After the second reading, the coding process began. According to Charmaz (2006), coding interview transcripts line by line helps data to remain open besides determining the samples' implicit or explicit concerns of an issue. After the coding was completed, cross-case comparison was made to compare and contrast the sample responses before themes across the interviews data were identified. The codes produced were then converged into categories and eventually formed themes that represent the findings of the study. 
Table 1. Application of the Wolcott (1994) strategies to ensure trustworthiness of the research

\begin{tabular}{|ll|l|}
\hline $\begin{array}{l}\text { Wolcott Strategies } \\
\text { (Wolcott, 1994) }\end{array}$ & \multicolumn{1}{c|}{ Description } \\
\hline i. & $\begin{array}{l}\text { Talk a little, } \\
\text { listen a lot }\end{array}$ & $\begin{array}{l}\text { The researcher patiently waited for the responses particularly for interviews that were conducted in English. While } \\
\text { waiting, the researcher also thought of some other probing questions instead of giving any hints that might } \\
\text { influence the samples' responses. }\end{array}$ \\
\hline ii. & $\begin{array}{l}\text { Record } \\
\text { accurately }\end{array}$ & $\begin{array}{l}\text { Although the interviews were fully audio-recorded, the researcher still jotted down some important responses from } \\
\text { the interviewees during the interview session. Later on, the researcher could compare what was recorded with } \\
\text { what was written to ensure accuracy of information. }\end{array}$ \\
\hline iii. & $\begin{array}{l}\text { Begin writing } \\
\text { early }\end{array}$ & $\begin{array}{l}\text { This strategy was applied while conducting the observations. The reflection part of the field note was written right } \\
\text { after the class dismissed. This action revealed what questions need to be asked in the following day or how to focus } \\
\text { the observation (Gay et al, 2009) }\end{array}$ \\
\hline iv. & Report fully & $\begin{array}{l}\text { This strategy was applied during the report writing stage. The process involved reporting all kinds of data } \\
\text { including discrepant data or data that were unfavourable to the research aims. It might be helpful to reflect and } \\
\text { seek further explanation about what was actually happening in the setting. }\end{array}$ \\
\hline v. & $\begin{array}{l}\text { Seeking } \\
\text { feedback }\end{array}$ & $\begin{array}{l}\text { The interview transcripts (verbatim transcription of the interview session) were given to the respective } \\
\text { interviewees for them to verify that what were written in the transcription were their genuine response. The } \\
\text { participants were also required to put their signature at the last page of the transcription to mark their verification. }\end{array}$ \\
\hline vi. & $\begin{array}{l}\text { Write } \\
\text { accurately }\end{array}$ & $\begin{array}{l}\text { It was necessary for the researchers, whose English is not their first language, to determine the clarity of the } \\
\text { communication patterns. This was achieved by using English proof-reading services. }\end{array}$ \\
\hline
\end{tabular}

\section{Research Trustworthiness}

Trustworthiness, a term coined by Guba (1981), serves to ensure rigour in qualitative research paradigms without neglecting the relevance of a qualitative research. To enhance the trustworthiness of the research, the researcher adopted the many strategies suggested by Wolcott (1994), such as talk a little, listen a lot, record accurately, begin writing early, report fully, seeking feedback, and write accurately. Table 1 highlights how these strategies were used throughout the data collection phase.

\section{Findings and Discussions}

The findings are presented based on the themes that emerged from the data analysis. Succinctly, three themes were derived, namely (i) knowledge and awareness on SCL, (ii) optimism towards SCL, and (iii) challenges and misinterpretation of SCL. These findings corroborate with the direct excerpts from the interview transcripts and have been discussed in various perspectives in the literature.

\subsection{Knowledge and Awareness on SCL}

All the sample s were well equipped with the knowledge on twenty-first century learning and also managed to picture SCL as one of the learning methods that emphasise students' learning. The samples were aware that SCL is an approach that encourages students to actively participate in learning while their teachers act only as facilitators. Two of the samples stated:

In SCL, students explore their own knowledge and actively involved themselves in learning activities. Teachers promote sharing of knowledge in class and act as facilitators in the learning processes. (I1_12) In SCL, students will search for information by themselves and teachers role is to clarify and promoting

\section{thinking skills among students. (I2_09)}

The above statements are promising because understanding the rationale behind SCL is prerequisite to a successful implementation of SCL in secondary-school classrooms. The key success of SCL implementation on teacher part is a thorough comprehension of the model principles and genuine recognition of its value. The samples' understanding of SCL appears to be aligned with the concept of SCL noted in previous studies. As stated by Woolfolk (1998), students would work independently to ascertain and discover some principles of knowledge in SCL. Carlile and Jordan (2005) also mention that SCL allows students to carry out their own activities in examining particular concepts. SCL is also a learning approach that encourages deep learning among students.

When asked about examples of activities in SCL, the samples were able to state a variety of relevant group-based activities, such as group discussion, learning through experiments, and inter-group discussion, as indicated in the following statements:

Students will sit in group and carry out an experiment to test a hypothesis. Students will then solve the problems collaboratively and write an experiment report based on the result of the experiment or investigation. So students learn among them. (I1_17)

Group presentation is always carried out for the students who are excellent in studies. (I4 17)

For certain topics, I always asked my students to present in group so that they will also learn from their friends. (I7_7)

I sometime conducted discussion session in my class, be it whole class discussion or in group discussion. I can get may different ideas by doing this. (I5_5)

The findings also suggest that the sample s were aware of the importance or benefits of group discussion. In a group discussion, students will be given an opportunity to 
search for relevant information for a related topic and then will be asked to present their ideas to peers and teachers. The samples also acknowledged the benefits of group work during a teaching and learning session. They were aware about" harvesting" a variety of ideas during group discussion (whole class discussion or group discussion). Also apparent is the element of peer learning, in which students will learn not only from teachers, but also from their group members or members from other groups.

\subsection{Optimism towards SCL}

SCL is an approach that will help students to develop their learning skills and motivate them to practice lifelong learning (Boud \& Feletti, 1997). When students collaborate with others in a group discussion, their communication skills can be developed. The samples also believed that SCL will help to improve the students' capability of learning and searching for information independently. As stated by some of the samples:

$S C L$ will motivate the students to learn by their own and students will learn to talk or present their ideas in the public. (I1_21)

Through SCL, students learn to search for information through mass media. (I2_18)

In this age, they should not rely on me, they should rely on their self, on their group peers to learn. This is a lifelong learning process (I5_5).

The above findings are aligned with Kramer et al. (2007) who state that students will be more responsible and self-governing in their learning through SCL. The sample s' views also correspond to the view of Cheang (2009), who suggest that SCL will strengthen students' thinking skills and enhance their meta-cognitive self-regulation. At the digital age of knowledge which is ubiquitous and can be reached at fingertips, teachers should encourage students to explore the knowledge beyond classroom so that they can become independent learners. Students can be prompted through a variety of interesting and challenging tasks, which will motivate them to investigate certain topic thus enabling them to increase their understanding in particular science subjects. Hence, the students need skills to learn and they must not merely be provided with mass of knowledge.

The samples acknowledged that SCL will somehow benefit the students only if the method is planned systematically and only if all the barriers can be unraveled. This point of view is evident in the following excerpts:

A well-planned SCL in classroom will benefit the students. The classroom must be conducive in order to implement SCL including the suitable arrangement of studying desk to enable activities of SCL to be carried out. (I3_25)

SCL practice somehow depends on the internet access and fast internet access will help in implementing SCL in classroom where students can access to the information needed easily. (I4_28).

The above excerpts suggest that the classrooms in Malaysian secondary schools are equipped with proper facilities (i.e.: studying desk and internet access) which that can be utilised to promote SCL. For example, the chairs and desks are removable and can be re-arranged to form a suitable group seating or circular seating, which will promote student-to-student communication. Utilising the existing resources might be a better measure to begin the SCL rather than investing on new facilities. Besides, the place for learning can be extended to other places like libraries or even the school's mini garden. Such measures will motivate students to participate actively in exploring new knowledge. Generally, science laboratories can be found in all Malaysian secondary schools. These facilities will prepare students for all activities related to scientific investigation. The availability of laboratories also provides opportunities for students to test a theoretical concept that they have learnt from textbook. Such an activity can be one of the SCL activities that can be feasibly implemented in school.

Internet now has become an integral part to promote SCL particularly when it comes to searching for information and resources. O'Neill and Mcmahon (2005) in their research also state that proper resources and facilities are vital for SCL implementation in classroom. However, internet access can be hampered by poor connection, and therefore, teachers must be free to carry out other activities that do not require access to internet to promote SCL in classroom. Cooper et al. (2000) suggest that activities such as think-pare share, minute papers, and peer instruction to make SCL feasible.

From student readiness perspectives, Tseng, Chiang and Hsu (2008) in their research concluded that when students learn using an SCL approach for the first time, they would need more time to adapt to the new ways of teaching, such as team-work and learning problem solving. The progressive model of SCL paradigm needs to be applied here to prevent any rejection from students towards SCL. This implies that the implementations of SCL are parallel with a student's preparation periods. As noted by some of the samples, students' lack of learning skills might lead to misconception if they are fully in control of their own learning process. Two samples noted:

Most of the students are not able to search for information independently and they need guidance from the teachers. Some topics in pure Science are difficult and some of the students will have misconception of some concepts if they are not guided in a proper way (I3_38).

SCL is good of course, but we as teachers need to aware that students should be prepared for it (I7_33).

During the early introduction of SCL, teachers need to guide students and focus on the learning skills that the students need to be equipped with. These learning skills are vital to ensure the smooth sailing of SCL. Students will not 
be acquainted with information literacy if they are not guided from the beginning. As the learning process progresses, teachers might give a little bit more authority to the students for them to demonstrate their learning independency. This can be done by acknowledging the students' resources, ideas, and proposals. Towards the end of the process, students would become more comfortable with SCL hence becoming more independent learners. At this stage, teachers will give guidance only when needed and will monitor the student's learning from a distance.

\subsection{Challenges and Misinterpretation of SCL}

The samples were also in dilemma between promoting deep understanding and covering the syllabus in a SCL classroom. One of the samples pointed out:

In group presentation, students will only search for the information according to the topic given to their particular group. (I3_43)

The students would focus on a specific subtopic without searching for information for the topics given to other groups; yet, they can always learn about the other subtopics by asking the members of other groups in order to present their finding and discussion. Meaningful knowledge transfer will occur when the students are actively involved in presenting and arguing ideas with each other. As pointed out by Willington (2006), SCL promotes a meaningful learning process, and therefore ignoring SCL is equal to promoting information feeding instead of deeper understanding, which will equip learners with useful skills in the future.

Time factor is another constraint consistently mentioned by the samples. They believed that adopting SCL will take much time hence risking successful completion of a syllabus. As stated by one of the samples:

By carrying out SCL, I will not be able to finish my syllabus (I3_33).

I need to carry out extra classes during the weekend in order to finish my syllabus in physics, time is the main constraint for me to adopt SCL (I2_35).

Lack of time should not be the bottleneck to adopting SCL in Malaysian secondary schools. This obstacle can be solved by handling SCL activities in a more systematic way. Teachers can adjust their approach by planning SCL activities earlier for a certain topic. Well-planned activities will ensure successful implementation of SCL. For example, in order to carry out a group presentation, the topic should be given to the students earlier to ensure that the students will have sufficient time to search for information and prepare for presentation. Teachers need to learn to adapt themselves and be ready to make change when it is appropriate to do so. Continually reflecting on their teaching style will help teachers to understand how and what to change in order to meet the special needs of the students in SCL.
Looking from the larger perspectives of SCL implementation, a systematic change will ensure a successful and sustainable practice of SCL classroom (Borhan \& Yassin, 2013). Heavy syllabuses that are content-laden are more appropriate to teacher-centred learning because the contents focus merely on the attainment of knowledge. In contrast, syllabuses that put equal emphasis on the attainment of knowledge and acquisition of skills will correspond to student-centred learning. Subsequently, performance-based, alternative assessments should also be adopted in the curriculum in order to determine the extent to which a student has acquired the desired skills and competencies.

However, when asked to dichotomise the types of approach adopted either as students-centered or teacher-centered, the samples admitted that teacher-centered learning is still the dominating approach in their classroom practice. Some of the science teachers preferred teacher-centered learning to SCL, as evident in the following excerpts:

No. I did not practice SCL in my Physic classroom as my students still need my explanation before they can truly understand a physic concept. (I2_14)

In SCL, students do things (learn) by themselves, and I as a teacher cannot explain the knowledge or concept to them anymore. I'm afraid that they will not learn. (I6_50)

The above statements indicate that the samples believed that explaining to students is not needed in SCL. This perception should be corrected because in SCL, explaining to students is still needed particularly by Malaysian students who are used to teacher-centred learning. Teachers can play an important role by helping and encouraging students to actively participate in learning or by asking questions throughout the learning process in order to provoke critical thinking among the students. Teachers should inspire students to embrace SCL besides enhancing their desire to be actively involved in SCL. The transition process from teacher-centred to student-centred will not take place in an abrupt manner and therefore should be expected to progress gradually. SCL will lead to the independency, self-paced among the learners, which can be achieved only through progressive transition.

Another prevalent misinterpretation of SCL is the perceived difficulty of learning topics in SCL. The sample believed that only "easy topic" or "easily understood topics" are suitable for SCL, implying thus the method is suitable only for topics that involve low cognitive ability. The following excerpts exemplify such claims:

Nevertheless, teachers are free to adopt SCL if they think it is suitable for their class or maybe suitable for certain topics which are easily understood. (I4_31)

It is difficult to implement SCL for complex topics. SCL can only be implemented for easy topics. (I5_13)

I did not force the teachers to adopt $S \bar{C} L$ in their classroom as Science subject is a complex subject that 
needs deeper understanding of some concepts and freedom is given to the teachers whether to practice SCL or not. (I3_29)

In a SCL learning environment, students are expected to enhance their learning skills of collaboration, communication, creative, and critical skills. In achieving those skills, they need to work on real problem and meaningful activities to push them further. That "real-problem" or "meaningful activities" is always derived from complex issues or contents. The excerpt also states that the samples were aware about the need to impart deep understanding among the students but do not link the deep understanding with SCL. From theoretical perspectives, SCL is the method that will promote deep understanding in learning because students are required to independently learn by seeking the information and building the knowledge from their prior knowledge, which in turn, will promote deep understanding of learning.

In general, the samples who participated in this study were ready to implement SCL in their classroom. They were fully aware on the shift of roles among teachers and students in SCL classroom. In SCL, students are expected to be more independent, and to have more responsibility towards their learning. These students should become actively engage during the learning process. In a similar way, the role of the teacher will shift to becoming a facilitator to assist students to achieve their learning outcome. The samples also indicated high optimism towards SCL implementation. They related the readiness of facilities (e.g.: movable chair and desk for fluid setting of learning, good internet connection) as an important factor in ensuring successful implementation of SCL. They also posited that students should be made ready prior to SCL inception because they are not quite familiar to learning through SCL. A few of the samples linked SCL implementation with its challenges. The dilemma was between promoting deep learning in SCL and finishing the syllabus content as planned. Such a dilemma would create another challenge of time constraints in adapting SCL. Also noted that the students will still require teacher's explanation, hence the misconception that SCL is not suitable for their classes. Another misconception is that SCL is suitable only for easy topics, which contradict SCL principles. Teacher should not call off their explanation in SCL class especially during the early phase of SCL implementation to avoid conflict among students. As for the compatibility between SCL and difficult topics, SCL stands on the premise of promoting Higher Order Thinking Skills (HOTS) and difficult topics, which often demand learners to utilise their higher-order thinking skills.

\section{Insight for PBL Module Development}

On the basis of the findings, a problem-based learning
(PBL) module for a science topic will be developed. By utilising the empirical information in developing an educational module, it is hoped that the module will correspond to the local conditions and resemble the current practice. As the data suggest, the readiness to implement SCL among the school administrators appears to be in the middle of a continuum. The samples were optimistic about implementing SCL in classroom, but were hesitant due to the perceived challenges. Implementing PBL should be in a progressive manner. PBL may be introduced to a small yet manageable learning unit in order to avoid cultural shock among students, who are used to learning by means of teacher-centred learning. The following insights were derived from the findings:

- Before any implementation takes place, students need to be trained to be better prepared for PBL. The training can be in the form of running a simple workshop during out-of-class time to expose them to PBL scenario, the learning process. And the assessment. A guidebook can also be useful to help them see the importance of learning through PBL. Students nowadays need justification and rationale of doing any action. Otherwise, they will not foresee the importance of PBL.

- $\quad$ Facilitation is one of the PBL hallmarks. At the early phase of PBL implementation, teachers should employ a more concrete and structured facilitation. This measure serves to support student learning and to sustain their motivation in learning through PBL. As the PBL class proceeds, teachers may reduce the amount of facilitation to allow more authority for students to manage their learning. Towards the end, the students are expected to develop a kind of independency in their learning.

- $\quad$ A PBL class starts with a problem scenario that serves as a focus point of learning. The problem scenario can be loosely or highly structured depending on the ability of the learners. A good problem scenario is designed to consider students' previous experience, is able to engage students in learning, is able to inculcate learning skills, and will drive students towards their learning goals. The findings imply that a highly structured problem scenario may be introduced at the early phase of PBL implementation to familiarise students with dealing with the problems, and to allow them to progressively develop their skills in dealing with the problems. As the implementation proceeds, a less structured problem scenario may be introduced to enhance the students' skills.

- $\quad$ Facilities and learning spaces are perceived as barriers for the teachers to implement SCL in their classrooms. The existing facilities and learning space were still considered feasible for PBL implementation. Because PBL emphasises group work, teachers can always plan and rearrange the classroom to encourage group discussions. 


\begin{tabular}{|c|c|c|c|}
\hline \multirow{2}{*}{$\begin{array}{c}\text { Stage of } \\
\text { Implementation }\end{array}$} & \multicolumn{3}{|c|}{ Aspect of Continuum } \\
\hline & PBL Problem Scenario & Training, PBL Guide and support & Facilitation \\
\hline Early & 1 & & \\
\hline Middle & & & \\
\hline \multicolumn{4}{|l|}{ Late } \\
\hline & $\begin{array}{l}\text { Difficulty of Problem Scenario is } \\
\text { increased towards the late stage of } \\
\text { implementation }\end{array}$ & $\begin{array}{l}\text { Training, PBL Guide and support for } \\
\text { both teachers and students along the } \\
\text { stage of implementation }\end{array}$ & $\begin{array}{l}\text { Amount of facilitation is } \\
\text { decreased towards the late stage } \\
\text { of implementation }\end{array}$ \\
\hline
\end{tabular}

Figure 1. Visualisation and summarises of the aforementioned insights into a continuum of PBL implementation

\section{Conclusions}

The interviews with the samples provided valuable information on the current status of SCL implementation in a Malaysian secondary school. The findings indicate that the samples were aware of SCL as an approach to motivating students to participate actively in learning and to encouraging a meaningful learning process. They were indeed aware about the new paradigm shift from teacher-centeredness to students-centeredness in the context of Malaysian secondary school. The samples also addressed the role of teachers as facilitators that help students to engage in learning and thus inspiring their ability to explore new knowledge in SCL.

However, the findings also indicate that the implementation of SCL in the selected secondary school is still in its infancy and that teacher-centered learning is the dominant learning style. Some challenges are anticipated in implementing SCL in school, and therefore, making the students participate actively in learning can be a massive task. A gradual stage-by-stage implementation of SCL in secondary school can be an alternative measure to ensure successful implementation of SCL. While challenges are prevailing in every learning classroom, they can be countered by a few strategies as propose by the insights for PBL module development. In particular, the continuum for PBL scenario, PBL facilitation and PBL guide, training and support should be mapped out to maximize its impact and ensure a smooth, if not successful PBL implementation. This micro-level PBL module development should be viewed as a preliminary foundation for a wider PBL implementation. An endeavour to set up SCL as a learning approach that introduces meaningful interaction between teachers and students will help SCL to gain popularity in Malaysian secondary school classrooms. Teachers who are willing to cope with changes will contribute to the successful implementation of SCL in classroom.

\section{Author Contributions}

For research articles with several authors, a short paragraph specifying their individual contributions must be provided. The following statements should be used "conceptualization, X.X. and Y.Y.; methodology, X.X.; software, X.X.; validation, X.X., Y.Y. and Z.Z.; formal analysis, X.X.; investigation, X.X.; resources, X.X.; data curation, X.X.; writing - original draft preparation, X.X.; writing-review and editing, X.X.; visualization, X.X.; supervision, X.X.; project administration, X.X.; funding acquisition, Y.Y.”,

\section{Funding}

This research received no external funding

\section{Conflicts of Interest}

The authors declare no conflict of interest. 


\section{REFERENCES}

[1] Boud, D. \& Feletti, G. I. (1997). The Challenge of Problem-based Learning, 2nd edition. London: Kogan Page.

[2] Borhan, M. T. (2012). Problem-based Learning (PBL) in Malaysian Higher Education: A Review of Research on Learners' Experience and Issues of Implementation. ASEAN Journal of Engineering Education, 1(1), 48-53.

[3] Borhan, M. T. \& Yassin, S.M. (2013). Implementation of Problem Based Learning (PBL) in a Malaysian Teacher Education Course: Issues and Benefits from Students Perspectives.in K Mohd-Yusof, D Arsat, MTB Borhan, E de Graaff, A Kolmos, FA Phang, PBL across Cultures. (181). Aalborg Universitetsforlag.

[4] Cannon, R. \& Newble, D. (2000). A Guide to Improving Teaching Methods: a handbook for teachers in university and colleges (London, Kogan Page).

[5] Carlile, O., \& Jordan, A. (2005). It works in practice but will it work in theory? The theoretical underpinnings of pedagogy. In S. Moore, G. O’Neill, \& B. McMullin (Eds.), Emerging Issues in the Practice of University Learning and Teaching. Dublin: AISHE

[6] Charmaz, K. (2006). Constructing grounded theory: A practical guide through qualitative analysis. London: Sage Publications.

[7] Cheang, K. I. (2009). Effects of learner-centered teaching on motivation and learning strategies in a third-year pharmacotherapy course. American Journal of Pharmaceutical Education, 73(3), Available:http://dx.doi.o $\mathrm{rg} / 10.5688 / \mathrm{aj} 730342$

[8] Cooper, J. L., MacGregor, J., Smith, K. A., \& Robinson, P. (2000). Implementing small-group instruction: Insights from successful practitioners. New Directions in Teaching and Learning, 81, 64-76.

[9] Cuban, L. (1991). History of teaching in social studies, in J.P Shaver (1991)(ed) Handbook of Research on Social Studies Teaching and Learning. New York: Macmill

[10] Duch, B. J., Groh, S. E, \& Allen, D. E. (Eds.). (2001). The power of problem-based learning. Sterling, VA: Stylus.

[11] Gay, L. R., Mills, G. E., and Airasian, P. (2012). Educational Research: Competencies for analysis and applications. (10th Edition): New Jersey.

[12] Gibbs, G. (1992). Assessing more students. Oxford: Oxford Brookes University.

[13] Guba, E. G. (1981) Criteria for Assessing Trustworthiness of Naturalistic Inquiries. Educational Communication and Technology Journal, 29, 75-91.

[14] Kramer, P., Ideishi, R., Kearney, P., Cohen, M., Ames Oppermann, J., Borelli Shea, G., Schemm, R.,\& Blumberg, P., (2007). Achieving curricular themes through learner-centered teaching. Occupational Therapy in Health Care, 27(1/2), 185- 198. Retrieved on March 10, 2019 from Academic Search Premier.

[15] O’Neill, G., \& McMahon, T. (2005). Student-Centered Learning: What does it mean for students and lecturers? In S. Moore, G. O’Neill, \& B. McMullin (Eds.), Emerging Issues in the Practice of University Learning and Teaching. pp. 27-36. Dublin: AISHE.

[16] Tseng, K.H., Chiang, F.K., \& Hsu, W.H. (2008). Interactive processes and learning attitudes in a web-based problem-based learning (PBL) platform. Computers in Human Behavior, 24, 940-955.

[17] Willington, J. (2006). Secondary education: The key concepts. London: Routledge Tylor and Francis Group

[18] Wolcott, H. F. (1994). Transforming qualitative data: Description, analysis and interpretation, Thousand Oaks, CA.

[19] Woolfolk, A. E. (1998). Educational Psychology (7th ed.). Boston, MA: Allyn and Bacon. 